\title{
PERSEPSI DAN SIKAP REMAJA TENTANG SEKS PRANIKAH DENGAN KEJADIAN KEHAMILAN PRANIKAH DI KELURAHAN RUMBALIBUNGA KOTA TIDORE KEPULAUAN TAHUN 2017 Nurkila Suaib*) \\ Jurusan Kebidanan, Politeknik Kesehatan Kemenkes Ternate Email : nurkilas81@yahoo.co.id
}

\begin{abstract}
ABSTRAK
Latar Belakang : Berdasarkan data World Health Organization (WHO) Tahun 2010, sekitar 16 juta perempuan berusia 15-19 tahun melahirkan setiap tahunnya, sekitar 11\% dari semua kelahiran di seluruh dunia. Wanita yang hamil pada usia 15-19 tahun mempunyai risiko yang lebih besar untuk mengalami komplikasi kehamilan dan persalinan dibandingkan wanita yang hamil pada usia 20-24 tahun (Aera, 2012). Tujuan Penelitian :Mengetahui Hubungan persepsi dan sikap remaja tentang seks pranikah dengan kejadian kehamilan Pranikah di Kel. Rumbalibunga Tahun 2017. Metode Penelitian : Penelitian ini merupakan jenis penelitian Observasional dengan rancangan penelitian Cross sectional. Hasil Penelitian: Menunjukkan adanya hubungan yang sangat positif antara Persepsi dan Sikap Remaja dengan Kehamilan Pranikah di Kelurahan Rumbalibunga dengan menunjukkan nilai signifikansi 0.001 atau lebih kecil 0.05. Kesimpulan: Terdapat Hubungan Persepsi dan Sikap Remaja tentang Seks Pranikah dengan Kehamilan Pranikah di Kelurahan Rumbalibunga Kota Tidore Kepulauan.
\end{abstract}

$\begin{array}{ll}\text { Kata Kunci } & : \text { Persepsi, Sikap dan Kehamilan Pranikah } \\ \text { Daftar Pustaka } & : 16(2006-2016)\end{array}$

\section{Pendahuluan.}

Dunia remaja merupakan suatu tahap yang kritikal didalam kehidupan manusia, yaitu peralihan dari dunia anak-anak menuju ke dunia dewasa. Kehidupan remaja merupakan kehidupan yang sangat menentukan bagi kehidupan masa depan mereka selanjutnya. Di tahapan ini seseorang memulai untuk mencari identitas dan penampilan diri. Bahkan pakar psikologi mengistilahkan dunia remaja sebagai "emotional age" (umur emosi). Tetapi faktor yang bisa mempengaruhi moral remaja juga akan mempengaruhi ketika dia menginjak dewasa (Mey, 2013).

Berdasarkan data World Health Organization (WHO) Tahun 2010, sekitar 16 juta perempuan berusia 1519 tahun melahirkan setiap tahunnya, sekitar $11 \%$ dari semua kelahiran di seluruh dunia. 95\% dari kelahiran remaja terjadi di negara-negara berkembang. Menurut WHO usia 1020 tahun adalah usia remaja, di mana usia-usia tersebut mempunyai risiko yang lebih tinggi dari pada kehamilan dalam usia-usia di atasnya. Wanita yang hamil pada usia 15-19 tahun mempunyai risiko yang lebih besar untuk mengalami komplikasi kehamilan dan persalinan dibandingkan wanita yang hamil pada usia 20-24 tahun (Aera, 2012).

Hasil riset dari penelitian yang telah dilakukan oleh Komisi Nasional(KOMNAS) Perlindungan Anak (2007) ataupun BKKBN (2010), mengenai perilaku remaja yang melakukan hubungan seks pra nikah, menunjukkan kecenderungan 
meningkat. Data hasil riset $\mathrm{BKKBN}$ misalnya, mengatakan bahwa separuh remaja perempuan lajang yang tinggal di wilayah Jakarta, Bogor, Tangerang, dan Bekasi telah kehilangan keperawanan dan mengaku pernah melakukan hubungan seks sebelum menikah, bahkan tidak sedikit yang mengalami kasus hamil di luar nikah. Ironisnya temuan serupa ternyata juga terjadi di kota-kota besar lainnya seperti Surabaya, Medan, Bandung, dan Yogyakarta (Darsono, 2013).

Kecenderungan perilaku seks bebas dikalangan usia 13 hingga 18 tahun ini tentu saja membawa dampak tidak hanya pada rentannya kesehatan alat reproduksi, selain meningkatnya kasus penularan penyakit infeksi HIV/AIDS, tetapi juga tingginya jumlah kasus kehamilan di luar nikah yang memicu masalah lain. Yaitu meningkatnya jumlah praktek aborsi ilegal. Perilaku seks bebas di kalangan remaja ini mungkin hanya salah satu implikasi masalah dari sederet persoalan yang dihadapi anak dan remaja dimasa sekarang (Darsono, 2013).

Berdasarkan data yang didapat dari Puskesmas Rum Balibunga khususnya bagian Kesehatan Keluarga (Kesga), bahwa pada Tahun 2016total kehamilan di PKM Rum Balibunga adalah 201 orang terdapat kehamilan remaja sebanyak 12 orang $(6.7 \%)$, Persalinan Remaja 6 orang $(3,1 \%)$, Abortus terdiri dari 10 (5,7\%), dan 5 (50\%)diantaranya adalah Abortus pada kehamilan remaja. Menurut bagian Kesga, pada kenyataannya masih ada kejadian kehamilan remaja namun belum terdata.
Seks adalah kebutuhan dasar manusia dalam manifestasi kehidupan yang berhubungan dengan alat reproduksi.Sedangkan menurut WHO seksualitas adalah suatu aspek inti manusia sepanjang kehidupannya dan meliputi seks, identitas dan peran gender, orientasi seksual, erotisme, kenikmatan, kemesraan dan reproduksi (Dwi, 2013).

Chandranita

(2010), mengatakan bahwa pada mata rantai konsepsi (fertilisasi) dan implantasi (nidasi) terjadi perubahan rohani dan jasmani, karena terdapat

perubahan hormon spesifik dan menimbulkan gejala dan tanda hamil sebagai tanda dugaan hamil, tanda kemungkinan hamil, dan tanda pasti hamil.

Berdasarkan hal-hal tersebut maka penulis tertarik untuk melakukan penelitian dengan judul "Hubungan Persepsi dan Sikap Remaja Tentang Seks Pranikah DenganKejadian Kehamilan Di Kel. RumBalibunga Tahun 2017'.

\section{METODE PENELITIAN}

Penelitian ini merupakan jenis penelitian Observasional dengan rancangan penelitian Cross sectional. Populasi pada penelitian ini adalah seluruh Remaja yang pernah mengalami Kehamilan Pranikah, Sampelnya adalah seluruh Populasi yang berjumlah 30 orang. 
3. HASIL DAN PEMBAHASAN

Berdasarkan hasil penelitian

tentang Hubungan Persepsi dan Sikap

Remaja tentang Seks Pranikah dengan

Kehamilan Pranikah di Kelurahan

Rumbalibunga Kota Tidore Kepulauan yang dilakukan pada 30 Sampel, Maka diperoleh hasil sebagai berikut:

1. Persepsi

Tabel 1 Distribusi Frekuensi Perepsi

\begin{tabular}{l|r|r|r|c}
\hline \multirow{2}{*}{ Persepsi } & $\mathbf{f}$ & F & \multicolumn{2}{|c}{ Kumulatif } \\
\cline { 4 - 5 } & & $(\boldsymbol{\%})$ & $\mathbf{F}$ & $\mathbf{F}(\boldsymbol{\%})$ \\
\hline Buruk & 6 & 20 & 6 & 20 \\
\hline Baik & 24 & 80 & 24 & 80 \\
\hline Total & 30 & 100 & 30 & 100 \\
\hline
\end{tabular}

Sumber : Data Primer

Dari tabel 1 menunjukkan bahwa prosentasi remaja yang memiliki persepsi baiksebesar (80\%) dibanding dengan remaja yang memiliki persepsi buruk sebesar $(20 \%)$ tentang seks Pranikah.

\section{Sikap}

Tabel 2 Distrubusi Frekuensi

Sikap

\begin{tabular}{l|r|r|r|r}
\multirow{2}{*}{ Sikap } & \multicolumn{2}{|c|}{ F } & \multirow{2}{*}{ F (\%) } & \multicolumn{2}{|c}{ Kumulatif } \\
\cline { 3 - 5 } & & & \multicolumn{1}{|c}{ f } & F (\%) \\
\hline Buruk & 4 & $\mathbf{1 3}$ & $\mathbf{4}$ & $\mathbf{1 3}$ \\
\hline Baik & $\mathbf{2 6}$ & $\mathbf{8 7}$ & $\mathbf{2 6}$ & $\mathbf{8 7}$ \\
\hline Total & $\mathbf{3 0}$ & $\mathbf{1 0 0}$ & $\mathbf{3 0}$ & $\mathbf{1 0 0}$
\end{tabular}

\section{Sumber : Dara Primer}

Dari tabel 2 menunjukkan bahwa prosentasi remaja yang memiliki sikap baik sebesar $(87 \%)$ dibanding dengan remaja yang memiliki persepsi buruk sebesar (13\%) tentang seks Pranikah.

Tabel 3

Ringkasan Hasil Pengujian Hipotesis Korelasi

\begin{tabular}{|c|c|c|c|c|c|c|c|c|}
\hline \multirow[b]{2}{*}{ Hipotesis } & \multirow{2}{*}{$\begin{array}{c}\text { Variabe } \\
\text { l yg } \\
\text { dikorela } \\
\text { sikan } \\
\text { dengan } \\
\text { Variabe } \\
\text { l Y }\end{array}$} & \multirow{2}{*}{$\begin{array}{c}\text { Koefe } \\
\text { sioen } \\
\text { Korel } \\
\text { asi }\end{array}$} & \multirow{2}{*}{$\begin{array}{c}\text { Statistik } \\
\text { Uji } \\
\text { T- Hitung / } \\
\text { F Hitung }\end{array}$} & \multirow[b]{2}{*}{$\begin{array}{c}\text { t - tabel/ } \\
\text { t- tabel }\end{array}$} & \multirow[b]{2}{*}{$\begin{array}{l}\text { Nilai } \\
\text { Sig. }\end{array}$} & \multicolumn{2}{|c|}{ Kriteria } & \multirow[b]{2}{*}{$\begin{array}{l}\text { Ket Hasil } \\
\text { Pengujian }\end{array}$} \\
\hline & & & & & & Nilai Sig. & Statistik Uji & \\
\hline H1 & $\mathrm{X} 1$ & 0.605 & 1.000 & 2.042 & 0.001 & Sig $<0.05$ & T Hitung > T Tabel & Signifikan \\
\hline H2 & $\mathrm{X} 2$ & 0.932 & 1.000 & 2.042 & 0.002 & Sig $<0.05$ & T Hitung > T Tabel & Signifikan \\
\hline H3 & $\mathrm{X} 1, \mathrm{X} 2$ & 0.605 & 1.000 & 2.042 & 0.001 & Sig $<0.05$ & T Hitung > T Tabel & Signifikan \\
\hline
\end{tabular}

Sumber : Analisis SPSS

Dari output di atas, diperoleh angka koefisien korelasi sebesar 0,605**. Artinya, tingkat kekuatan hubungan antara variabel persepsi remaja dengan kehamilan pranikah adalah sebesar 0,605 atau sangat kuat/besar. Tanda bintang (**) artinya korelasi atau hubungan bernilai signifikan pada angka sebesar 0,01.

Hasil pengujian pada hipotesis ketiga variabel bahwa terdapat hubungan antara persepsi dan sikap 
dengan kehamilan pranikah. Hal ini dapat dijelaskan karena adanya hubungan antara pesrsepsi dengan sikap sangatlah dekat.Pada penghitungan menggunakan uji korelasi keduanya berhubungansangatdekat dengan dilihat nilai $\mathrm{p}=0,000$. Hal inilah yang sangat berpengaruh dalam pengujian secara bersama atau yang disebut dengan autokorelasi.

Sejalan dengan hasil penelitian Mahmuda dkk bahwa ada hubungan yang bermakna secara statistic antara sikap dengan prilaku seksual remaja.

Sikap adalah respon tertutup seseorang terhadap suatu stimulus atau objek, baik yang bersifat internal maupun eksternal sehingga manifestasinya tidak dapat dilihat secara langsung, tetapi hanya dapat ditafsirkan. Sikap menunjukkan adanya kesesuaian respon terhadap stimulus tertentu. Sehingga dapat dipahami jika perilaku seksual berisiko banyak ditemukan pada responden yang memiliki sikap negatif terhadap berbagai perilaku seksual remaja. (Mahmuda, dkk, 2016)

Hasil penelitian sebelumnya yang dilakukan oleh Dewi (2007), bahwa dari 150 responden didapatkan sebanyak $88,7 \%$ remaja bersikap positif terhadap seksual (kecenderungan menghindari perilaku seksual pranikah). Hal ini disebabkan karena kebanyakan remaja memiliki persepsi bahwa seks sebaiknya dilakukan setelah ada ikatan perkawinan yang sah dan dihalalkan menurut agama. Mereka meyakini, jika melakukan seks bebas atau seks pranikah pada usia remaja akan berakibat buruk Terhadap masa depan dan perkembangan mental mereka (Jailani P Kadek dkk, 2014)

Persepsi merupakan proses pemahaman terhadap suatu objek yang merangsang panca indera dan Memungkinkan individu untuk membuat kontruksi dan prediksi tentang keseluruhan dari stimulus tersebut dari persepsi dirinya sehingga persepsi akan memberi warna dari perilaku individu. Masa remaja juga merupakan suatu periode dalam lingkungan kehidupan diantara masa kanak-kanak dan masa dewasa (Rudolph,2006).

Dalam hal ini para remaja banyak Mencari pengetahuan yang bersumber Dari manapun yang akhirnya akan menimbulkan persepsi masing-masingyang berbeda. Faktor yang mempengaruhi persepsi menurut Saleh dan Wahab (2004) ada beberapa antara lain; perhatian yang selektif, ciri-ciri rangsang, pengalaman

terdahulu,sikap, pendidikan, kepercayaan, dan lingkungan. Hasil penelitian ini mendukung dari penelitian sebelumnya yaitu (Anas Rahmat Hidayat, 2013).

\section{SIMPULAN}

Berdasarkan penelitian dengan judul Hubungan Persepsi dan Sikap Remaja tentang Seks Pranikah dengan kejadian kehamilan Pranikah di Kelurahan Rumbali bunga Kota Tidore Kepulauan Tahun 2017 dapat ditarik kesimpulan sebagai berikut :

Berdasarkan hasil Uji Statistik dengan Uji Hubungan Spearmen Rho terdapat 
hubungan Persepsi dan Sikap remaja tentang seks Pranikah dengan kejadian kehamilan Pranikah menunjukkan siginifikansi sebesar 0.001 atau lebih kecil dari 0.05 , artinya ada hubungan antara persepsi dan sikap remaja dengan kehamilan pranikah Kelurahan Rumbalibunga Kota Tidore Kepulauan Tahun 2017.

\section{Saran :}

a. Bagi Remaja

\begin{tabular}{lr}
\multicolumn{2}{c}{ Disarankan kepada remaja } \\
untuk lebih $\begin{array}{r}\text { menambah } \\
\text { pengetahuan }\end{array}$ & tentang \\
reproduksi sehat dengan \\
memanfaatkan sarana yang
\end{tabular}
ada seperti layanan remaja sehat di Puskesmas Rumbalibunga Kota Tidore Kepulauan.

b. Bagi Tenaga Kesehatan Tenaga kesehatan yang berada di Kelurahan Rumbalibunga lebih meningkatkan effort peningkatan pengetahuan remaja tentang kesehatan reproduksi khususnya di Kelurahan Rum dan Kota

Tidore Kepulauan pada umumnya.

c. Bagi Institusi

Institusi Pendidikan Kesehatan dalam hal ini Poltekkes

Kemenkes Ternate perlu bekerjasama dengan Lintas

Sektoral membentuk

Kelurahan Rum Balibunga

sebagai Daerah Binaan mengingat fenomena masalah kesehatan reproduksi yang semakin meningkat.

d. Bagi Peneliti selanjutnya.
Lebih mengekplorer hasil kajian dan telaah literatur, mengkaji lebih dalam dan spesifik terkait judul penelitian.

5. Ucapaan terima kasih kami sampaikan kepada Unit Penelitian dan Pengabdian Poltekkes Kemenkes Semarang yang telah memberikan informasi kepada peneliti untuk mempublikasikan penelitian kami.

\section{DAFTAR PUSTAKA}

Amalia, Dwi Riski. 2013. Konsep

Seksualitas Manusia, (Online)

http://dwirizkiamalia.blogspot. com/2013/05/konsep-

seksualitas-manusia.html, diakses pada bulan Mei 2017.

Chandranita, Ida Ayu dkk. 2009. Memahami Kesehatan Reproduksi Wanita. Jakarta: EGC.

Dewi, Ari Prestina. 2012. Hubungan karakteristik remaja, peran teman sebaya dan paparan pornografi dengan perilaku seksual remaja di kelurahan pasir gunung depok. (TESIS). FIK UI

Dwi. 2013. Peranan Orang Tua Pada

Remaja. (Online) http://rinidwiyanarosa.blogsp.c om/2013/08/peranan-orangtua-pada-remaja.html, diakses bulan November 2017.

Dian, Leovina Putri. 2012. Kehamilan

Remaja. (Online). http://dianleovinaputri.blogspo. com/2012/03/kehamilanremaja.html, Diakses bulanJuni 2017.

Fana, Aera. 2013. Kasus Kehamilan Semakin Meningkat. (Online) http://gelumbang.com/1399/re 
maja/kasus-kehamilan-remaja-

semakin meningkat.html,

Diakses bulan Juni 2017

Gentawangi, Darsono. 2013.

Fenomena Seks Bebas.

(Online)

http://darsonogentawangi.word press.com/2013/01/17/fenomen a-seks-bebas/, Diakses Bulan

November 2017

Iksan, Khairul. 2012. Konsep Persepsi.

(Online)

http://khairuliksan.blogspot.co

$\mathrm{m} / 2012 / 11 /$ konsep-

persepsi_19.html. Diakses

bulan Mei 2017

Kusmiran. 2011. Kesehatan

Reproduksi Remaja Dan

Wanita. Jakarta: Salemba

Medika

Pieter, Herri Zan. 2010. Pengantar

Psikologi Dalam Keperawatan.

Jakarta: Kencana

Medical Record Puskesmas Rum

Balibunga Kota Tikep data

tentang Kesehatan Reprodusi

Remaja dn KIA/KB Tahun 2015 dan 2016.

Rahmad Hidayat A, Hubungan Persepsi dan Sikap dengan Perilaku Seks Pranikah di SMU PGRI 1 Sragen Jawa Tengah,

Volume 4, Nomor 2, Hal.68-

75, Jurnal Permata Indonesia, November Tahun 2013.

Suyanto. 2009. Riset Kebidanan (Metodologi Dan Aplikasi). Jogjakarta: Mitra Cendekia

Setiawan, Ari \& Saryono. 2011. Metode Penelitian Kebidanan DIII, DIV, S1 Dan S2.

Yogyakarta: Nuha Medika

Sulistitaningsih. 2011. Metodologi

Penelitian Kebidanan:
Kuantitatif-Kualitatif.

Yogyakarta: Graha Ilmu

Widyastuti, Yani dkk. 2009. Kesehatan

Reproduksi. Yogyakarta: Fitramaya 